\title{
Recent Updates to Clinical Practice Guidelines for Diabetes Mellitus
}

\author{
Jin $\mathrm{Yu}^{1}$, Seung-Hwan Lee ${ }^{1,2}$, Mee Kyoung Kim ${ }^{3}$ \\ ${ }^{1}$ Division of Endocrinology and Metabolism, Department of Internal Medicine, Seoul St. Mary's Hospital, College of Medicine, \\ The Catholic University of Korea; ${ }^{2}$ Department of Medical Informatics, College of Medicine, The Catholic University of Korea; \\ ${ }^{3}$ Division of Endocrinology and Metabolism, Department of Internal Medicine, Yeouido St. Mary's Hospital, College of \\ Medicine, The Catholic University of Korea, Seoul, Korea
}

Guidelines for the management of patients with diabetes have become an important part of clinical practice that improve the quality of care and help establish evidence-based medicine in this field. With rapidly accumulating evidence on various aspects of diabetes care, including landmark clinical trials of treatment agents and newer technologies, timely updates of the guidelines capture the most current state of the field and present a consensus. As a leading academic society, the Korean Diabetes Association publishes practice guidelines biennially and the American Diabetes Association does so annually. In this review, we summarize the key changes suggested in the most recent guidelines. Some of the important updates include treatment algorithms emphasizing comorbid conditions such as atherosclerotic cardiovascular disease, heart failure, and chronic kidney disease in the selection of anti-diabetic agents; wider application of continuous glucose monitoring (CGM), insulin pump technologies and indices derived from CGM such as time in range; more active screening of subjects at high-risk of diabetes; and more detailed individualization in diabetes care. Although there are both similarities and differences among guidelines and some uncertainty remains, these updates provide a good approach for many clinical practitioners who are battling with diabetes.

Keywords: Diabetes mellitus, type 2; Consensus; Evidence-based medicine; Blood glucose

\section{INTRODUCTION}

The field of diabetes care is changing rapidly. Based on accumulating evidence on diverse aspects of diabetes management, clinical practice guidelines are updated in a timely manner. In

Received: 24 January 2022, Revised: 31 January 2022 ,

Accepted: 6 February 2022

Corresponding authors: Seung-Hwan Lee

Division of Endocrinology and Metabolism, Department of Internal Medicine, Seoul St. Mary's Hospital, College of Medicine, The Catholic University of Korea, 222 Banpo-daero, Seocho-gu, Seoul 06591, Korea

Tel: +82-2-2258-6069, Fax: +82-2-595-2534, E-mail: hwanx2@catholic.ac.kr

Mee Kyoung Kim

Division of Endocrinology and Metabolism, Department of Internal Medicine,

Yeouido St. Mary's Hospital, College of Medicine, The Catholic University of

Korea, 10 63-ro, Yeongdeungpo-gu, Seoul 07345, Korea

Tel: +82-2-3779-1368, Fax: +82-2-595-2534, E-mail: makung@catholic.ac.kr particular, some landmark clinical trials on newer anti-diabetic medications are changing the landscape of treatment strategies. Technological advances are also being applied for glucose monitoring and insulin treatment. Therefore, in this review, we summarize the major guidelines that have been updated recently and

\section{Copyright (C) 2022 Korean Endocrine Society}

This is an Open Access article distributed under the terms of the Creative Commons Attribution Non-Commercial License (https://creativecommons.org/ licenses/by-nc/4.0/) which permits unrestricted non-commercial use, distribution, and reproduction in any medium, provided the original work is properly cited. 
compare the differences between these guidelines.

\section{CLINICAL PRACTICE GUIDELINES FOR DIABETES MELLITUS OF THE KOREAN DIABETES ASSOCIATION}

The Committee of Clinical Practice Guidelines of the Korean Diabetes Association (KDA) updated the previous clinical practice guidelines for Korean adults with diabetes and published the seventh edition in May 2021 [1]. The updated statements endorsed a glycosylated hemoglobin (A1C) target of $6.5 \%$ for type 2 diabetes mellitus (DM) if it can be achieved safely [1]. In adults with recently diagnosed type $2 \mathrm{DM}$ and no clinically significant cardiovascular disease (CVD), glycemic control aimed at the near-normal range should be considered, with the aim of preventing the development of microvascular and macrovascular complications over the lifetime, if this goal can be achieved without substantial hypoglycemia or other unacceptable adverse consequences [1]. Table 1 summarizes the goal of glucose, blood pressure, and lipid control for patients with type 2 DM according to the KDA guidelines compared with other guidelines.

The treatment algorithm stratifies the strategy of glycemic control for type $2 \mathrm{DM}$ based on initial A1C levels and underlying comorbidities (Fig. 1). The largest change is more aggressive guidance that first recommends the use of specific drugs in patients with a specific disease or high-risk, deviating from the previous recommendations to start with metformin. The revised guidelines emphasize that injectable drugs are not the final treatment that is selected when there is no other option, but an option that should be considered in any circumstances.

After the initiation of therapy with a glucose-lowering agent, monotherapy or combination therapy should be provided on the basis of the target and current A1C levels. Initial combination

Table 1. Comparison of Glucose, Blood Pressure, and Lipid Control Targets in Type 2 Diabetes According to Current Global Guidelines

\begin{tabular}{|c|c|c|c|c|}
\hline & $\begin{array}{c}\text { Korean Diabetes } \\
\text { Association (KDA) [1] }\end{array}$ & $\begin{array}{c}\text { Japan Diabetes } \\
\text { Society (JDS) [65] }\end{array}$ & $\begin{array}{c}\text { American Diabetes } \\
\text { Association (ADA) [35] }\end{array}$ & $\begin{array}{l}\text { American Association of Clinical } \\
\text { Endocrinology (AACE) [17] }\end{array}$ \\
\hline \multirow[t]{3}{*}{$\mathrm{A} 1 \mathrm{C}, \%$} & $<6.5$ & $<6.0^{\mathrm{a}}$ & $<7.0$ & $<6.5$ \\
\hline & & $<7.0^{\mathrm{b}}$ & & \\
\hline & & $<8.0^{\mathrm{c}}$ & & \\
\hline \multirow[t]{2}{*}{ Blood pressure, $\mathrm{mm} \mathrm{Hg}$} & $<140 / 85^{\mathrm{d}}$ & $<130 / 80$ & $<140 / 90^{\mathrm{f}}$ & $<130 / 80$ \\
\hline & $<130 / 80^{\mathrm{e}}$ & & $<130 / 80^{g}$ & \\
\hline \multirow[t]{3}{*}{ LDL-C, mg/dL } & $<100^{\mathrm{h}}$ & $<120^{i}$ & $30 \%-49 \%$ & $<100^{\mathrm{n}}$ \\
\hline & $<70^{\mathrm{i}}$ & $<100(70)^{\mathrm{k}}$ & Reduction ${ }^{1}$ & $<70^{\circ}$ \\
\hline & & & $50 \%$ Reduction $^{\mathrm{m}}$ & $<55^{\mathrm{p}}$ \\
\hline Triglyceride, mg/dL & $<150$ & $<150$ & - & $<150$ \\
\hline \multirow[t]{2}{*}{ HDL-C, mg/dL } & $>40$ (men) & $\geq 40$ & - & - \\
\hline & $>50$ (women) & & & \\
\hline
\end{tabular}

A1C, glycosylated hemoglobin; LDL-C, low-density lipoprotein cholesterol; HDL-C, high-density lipoprotein cholesterol.

${ }^{a}$ Target when aiming for normal glycemia; individuals capable of achieving glycemic control with appropriate diet or exercise therapy or those capable of achieving glycemic control while on pharmacotherapy without developing hypoglycemia; ${ }^{\mathrm{b}}$ Target when aiming to prevent complications; ${ }^{\mathrm{c}}$ Target when

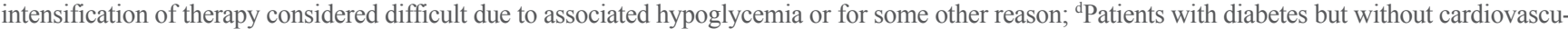

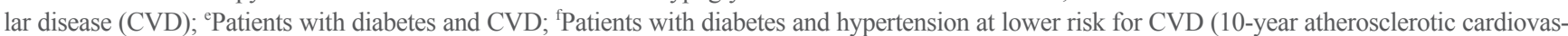

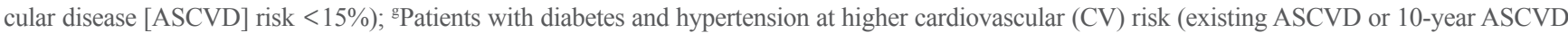

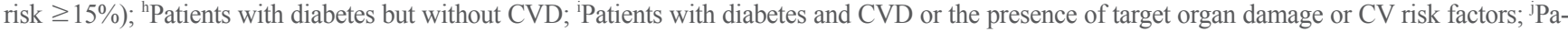
tients without a history of coronary artery disease; ${ }^{k}$ Patients with a history of coronary artery disease; for patients who also have high-risk conditions such as familial hypercholesterolemia and diabetes complicated by other high-risk conditions (noncardiogenic cerebral infarction, peripheral artery disease, chronic kidney disease, metabolic syndrome, overlap of major risk factors, and smoking), stricter LDL-C control should be considered, with a level of $<70 \mathrm{mg} / \mathrm{dL}$ as the target; 'There is no target value of LDL-C in the ADA guidelines. However, there are recommendations on the intensity of statin therapy according to the CV risk. For patients with diabetes aged 40-75 years without ASCVD, moderate-intensity statin therapy should be used. Moderateintensity statin regimens achieve $30 \%-49 \%$ reductions in LDL-C; ${ }^{\mathrm{m}}$ In patients with diabetes at higher risk, especially those with multiple ASCVD risk factors or aged 50-70 years, it is reasonable to use high-intensity statin therapy. High-intensity statin therapy will achieve approximately a 50\% reduction

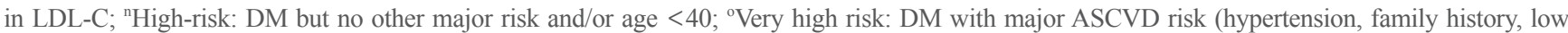

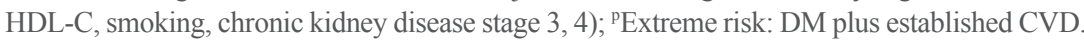




\section{Algorithm 1 | Initial therapy}

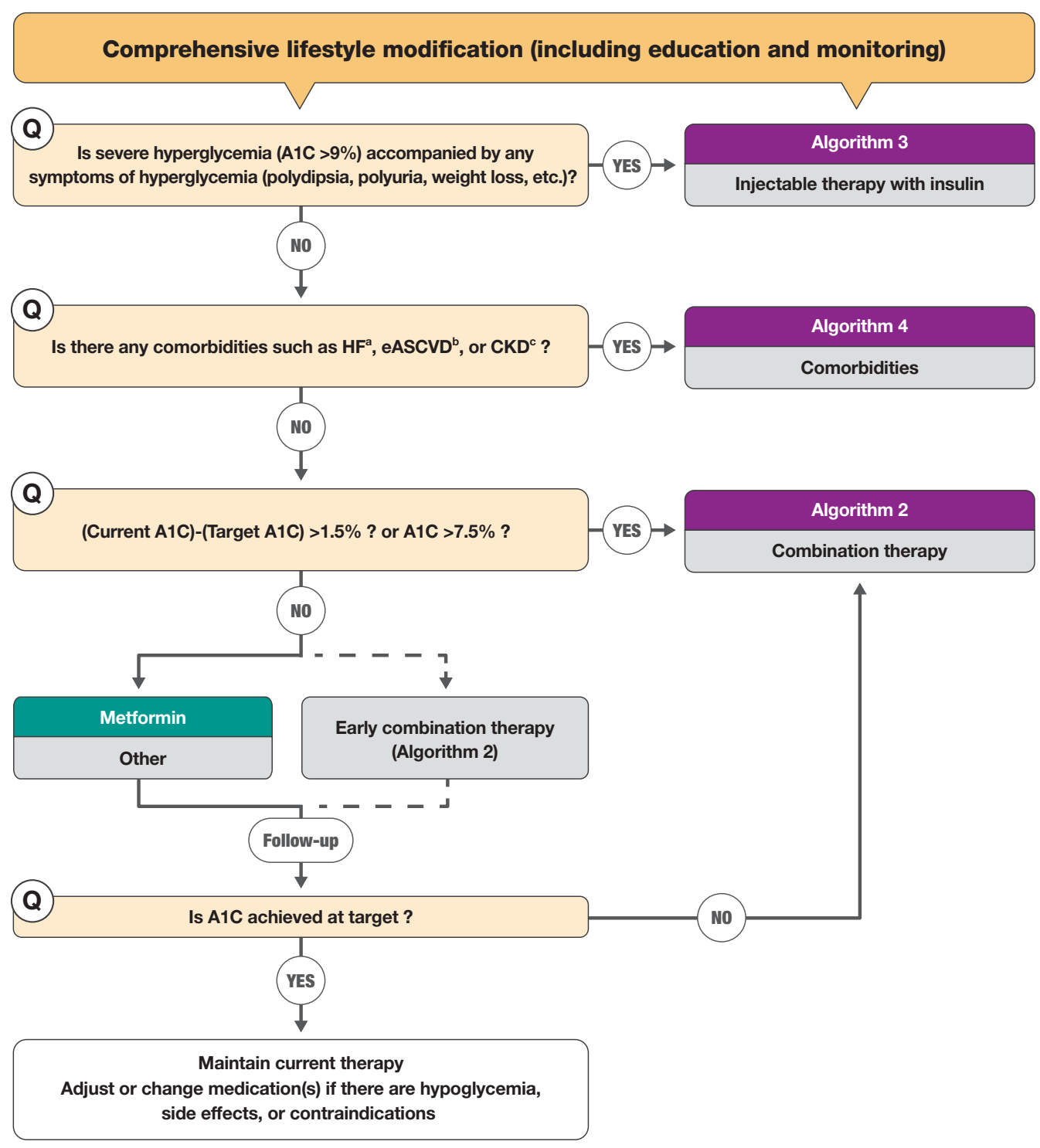

Fig. 1. Treatment algorithm 1 (initial therapy) for patients with type 2 diabetes mellitus (T2DM). The algorithm stratifies the strategy of glycemic control for T2DM based on initial glycosylated hemoglobin (A1C) levels and underlying comorbidities. For newly diagnosed T2DM, begin with comprehensive lifestyle modification (LSM) at the time of diagnosis and monitor continuously. If the initial severe hyperglycemia (A1C level $>9.0 \%$ ) is accompanied by symptoms of hyperglycemia, insulin treatment should be prioritized (algorithm 3). If heart failure (HF), established atherosclerotic cardiovascular disease (eASCVD), or chronic kidney disease (CKD) are present, follow algorithm 4. If glycemic target is not achieved within 3 months after LSM, then glucose-lowering agent should be initiated promptly. If the current A1C is $1.5 \%$ higher than that of the target A1C or the current A1C level is $>7.5 \%$, follow algorithm 2 (combination therapy). If the A1C level is $7.5 \%$ or less, metformin monotherapy is recommended as a first-line therapy. However, if there are contraindications or intolerable side effects related to metformin use, a different class of medications can be considered. Instead of metformin monotherapy, early combination therapy could be considered to reduce the risk of failure of glycemic control in some patients with newly diagnosed T2DM. Reprinted from

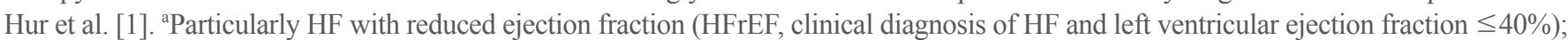
${ }^{\mathrm{b}} \mathrm{A}$ history of an acute coronary syndrome or myocardial infarction, stable or unstable angina, coronary heart disease with or without revascularization, other arterial revascularization, stroke, or peripheral artery disease assumed to be atherosclerotic in origin; ' ${ }^{2}$ stimated glomerular filtration rate $<60 \mathrm{~mL} / \mathrm{min} / 1.73 \mathrm{~m}^{2}$ or urine albumin creatinine ratio $\geq 30 \mathrm{mg} / \mathrm{g}$. 
therapy is recommended if the current $\mathrm{A} 1 \mathrm{C}$ is $1.5 \%$ to $2.0 \%$ higher than the target $\mathrm{A} 1 \mathrm{C}$. Insulin treatment should be prioritized if the baseline $\mathrm{A} 1 \mathrm{C}$ is $>9 \%$ and the patient is symptomatic (e.g., polydipsia, polyuria, or weight loss). It is recommended to consider any associated comorbidities (heart failure, established CVD, or chronic kidney disease [CKD]) when selecting a glucose-lowering agent. Regimens that include sodium-glucose cotransporter 2 (SGLT2) inhibitors or glucagon-like peptide 1 receptor agonists (GLP-1 RAs) with proven cardiovascular (CV) benefits should be prioritized for combination therapy in patients with established atherosclerotic cardiovascular disease (ASCVD) [2-10]. For patients with heart failure, SGLT2 inhibitors with proven CV benefits, should be prioritized [2-10]. For patients with albuminuria or reduced kidney function, SGLT2 inhibitors with proven renal and CV benefits should be prioritized $[9,10]$. Apart from recommending metformin as the firstline agent, SGLT2 inhibitors or GLP-1 RAs are recommended as first-line agents if there is a comorbidity such as ASCVD [1].

This updated guideline has new sections on continuous glucose monitoring (CGM), insulin pump use, and non-alcoholic fatty liver disease (NAFLD) in patients with DM. Thiazolidinedione or GLP-1 RAs can be used for the treatment of NAFLD in adults with type $2 \mathrm{DM}$, while metformin, dipeptidyl peptidase 4 inhibitors, vitamin E, and statins are not recommended for the treatment of NAFLD [11-13]. All adult type 1 DM patients should be encouraged to use real-time CGM devices to control blood glucose and lower the risk of hypoglycemia $[14,15]$. In addition, it has been suggested that adults with type $2 \mathrm{DM}$ who require multiple daily injections may use real-time CGM devices for glycemic control $[14,15]$. To reduce the risk of severe hypoglycemia for adult patients with type $1 \mathrm{DM}$ who experience severe hypoglycemia, insulin pumps, rather than multiple daily injections, are recommended even in the absence of CGM.

\section{AMERICAN ASSOCIATION OF CLINICAL ENDOCRINOLOGY CLINICAL PRACTICE GUIDELINE: THE USE OF ADVANCED TECHNOLOGY IN THE MANAGEMENT OF PERSONS WITH DIABETES MELLITUS}

The American Association of Clinical Endocrinology (AACE) published an updated guideline for available advanced diabetes technology in 2021 without updating their other guidelines on comprehensive type 2 diabetes management [16,17]. Clinical practice guidelines for this rapidly evolving field, encompassing CGM, insulin pump management, and the integration of CGM and pump therapy, have also been published. According to the AACE guideline on new diabetes technology, CGM is recommended for all people with diabetes treated with intensive insulin therapy, defined as three or more injections per day or use of an insulin pump [16,17].

Real-time CGM is recommended over intermittently scanned CGM for people with diabetes with problematic hypoglycemia who require predictive alarms [18-20]. Guidance on the CGM metrics for clinical decision-making is also included, according to which two metrics - time in range (TIR) and time below range (TBR) - should be used as the starting point for the assessment of the quality of glycemic control and as the basis for therapy adjustment, with an emphasis on reducing TBR when the percentages of CGM values falling below 54 or $70 \mathrm{mg} / \mathrm{dL}$ exceed targets (Table 2) [21]. These guidelines emphasize the need to check first by focusing on hypoglycemia (TBR) [16].

During the past decade, manufacturers have integrated CGM into pump technologies across a wide spectrum of devices, from sensor-augmented insulin pumps to low-glucose suspend and predictive low-glucose suspend systems to hybrid closed-loop systems, which are referred to as automated insulin dosing (AID) systems. Advances in technology have led to the development of AID systems, which have the ability to increase basal insulin delivery to address hyperglycemia, in addition to sus-

Table 2. Target Values of Continuous Glucose Monitoring Data for Most Adults with Diabetes

\begin{tabular}{lc}
\hline Variable & Target value \\
\hline Number of days of active CGM use & 14 days preferred \\
Percentage of data available from active & $>70 \%$ of data from 14 days \\
CGM use & \\
Mean glucose/glucose management indi- & Individualized to targets \\
cator (GMI) & $\leq 36 \%$ \\
Glycemic variability ( $\% \mathrm{CV}$, coefficient & \\
of variation) & $>70 \%$ \\
Percentage of time in range (\% TIR) 70 to & \\
$180 \mathrm{mg} / \mathrm{dL}$ & $<4 \%$ \\
Percentage of time below range (\% TBR) & \\
$<70 \mathrm{mg} / \mathrm{dL}$ & $<1 \%$ \\
Percentage of time below range (\% TBR) & \\
$<54 \mathrm{mg} / \mathrm{dL}$ & $<25 \%$ \\
Percentage of time above range (\% TAR) & \\
$>180 \mathrm{mg} / \mathrm{dL}$ & $<5 \%$ \\
Percentage of time above range (\%TAR) & \\
$>250 \mathrm{mg} / \mathrm{dL}$ & \\
\hline CGM, continuous glucose monitoring. &
\end{tabular}


pending insulin infusion to mitigate hypoglycemia. AID systems are strongly recommended for all people with type $1 \mathrm{DM}$, since their use has been shown to increase TIR, especially in the overnight period, without causing an increased risk of hypoglycemia [16,22,23]. Given improvements in TIR and the reduction in hyperglycemia with AID systems, this method of insulin delivery is preferred above other modalities. AID systems should be considered for people with diabetes who have suboptimal glycemia, significant glycemic variability, or impaired hypoglycemia awareness, or in whom permissive hyperglycemia is allowed due to the fear of hypoglycemia.

\section{STANDARDS OF MEDICAL CARE IN DIABETES OF THE AMERICAN DIABETES ASSOCIATION}

The American Diabetes Association (ADA) releases updated Standards of Medical Care in Diabetes every year in January [24]. Recent updates have focused on individualization of diabetes management in screening, intervention and care, use of technology, and prevention of complications [25]. Patient-centered care goals were emphasized in preventing type 2 DM. Overweight and obese adults at high-risk of type 2 DM are recommended to be referred to an intensive lifestyle and behavior change program. Individualized management of overweight and obese adults was also emphasized to prevent diabetes and comorbidities [26]. With developments of technology, it was recommended to consider technological assistance according to the individual's preference [27].

According to the most recent recommendations, screening for prediabetes and diabetes should begin at the age of 35 years [26]. The previous recommendation was that testing should begin at the age of 45 years. This change reflects the findings that opportunistic universal screening among individuals aged $\geq 35$ years could greatly reduce the national prevalence of undiagnosed prediabetes or diabetes at a relatively low cost. In the glycemic assessment section, TIR along with A1C has been more fully incorporated into the guideline [27]. A 14-day CGM assessment of TIR and use of a glucose management indicator can serve as a surrogate for $\mathrm{A} 1 \mathrm{C}$ in clinical management.

The use of metformin as the first-line therapy did not change, but individualization of treatment was emphasized. Although previous guidelines recommended the use of SGLT2 inhibitors and GLP-1 RAs in patients with CVD and/or CKD, the updated guideline recommends these treatments earlier [28]. In addition, the updated guideline reflects the adjustment to patient-centered treatment goals rather than sequential treatment to intensify treatment [29]. In the case of using insulin, GLP-1 RA combination therapy is still recommended, but it emphasizes combination therapy earlier [30-34].

In the diabetes care section, a comprehensive approach to reduce complications is recommended. Therapy includes management of glycemia, blood pressure, and lipids and the incorporation of treatment with benefits for CVD and/or CKD outcomes [35]. Patients with type 2 diabetes and ASCVD are recommended to use SGLT2 inhibitors and/or GLP-1RAs [2,4,10]. Patients with type 2 diabetes and established heart failure with a reduced ejection fraction are recommended to use SGLT2 inhibitors, as this class of medications has proven benefits for reducing heart failure and $\mathrm{CV}$ death $[8,36]$. Additional data on the benefits of SGLT2 inhibitors in decompensated heart failure and heart failure with preserved ejection fraction have been included in the updates [37,38]. The updated guideline recommends SGLT2 inhibitors in patients with stage $3 \mathrm{CKD}$ or higher and type 2 diabetes regardless of glycemic control [39]. For patients with type 2 diabetes and diabetic kidney disease, the use of SGLT2 inhibitors in patients with an estimated glomerular filtration rate of $\geq$ $25 \mathrm{~mL} / \mathrm{min} / 1.73 \mathrm{~m}^{2}$ and urinary albumin $\geq 300 \mathrm{mg} / \mathrm{g}$ creatinine is recommended to reduce CKD progression and CVD $[7,9,10$, 40]. GLP-1 RAs are also suggested for patients with CV risk to slow CKD progression [9]. A new recommendation is to use finerenone, a nonsteroidal mineralocorticoid receptor antagonist, to reduce CKD progression and CV events when it is not possible to use SGLT2 inhibitors [41,42].

The updates to the guideline include an extensive discussion of technology. The term "diabetes technology" is used to describe the hardware, devices, and software used to help diabetes patients manage their condition. The updates state that the individualization of technology type and selection is necessary both to prevent diabetes and to manage diabetes patients. Related education and evaluation of usage should also be conducted periodically [27]. The important point in the updates is that the active use of CGM devices has been added. The active use of CGM devices is now recommended from the early stage of diagnosis of diabetes requiring insulin management. In previous guidelines, CGM devices were only recommended for patients requiring multiple daily injections or continuous subcutaneous insulin infusion, but this year's recommendation extends to long-acting insulin (basal insulin) users [43,44]. The use of CGM devices is also recommended for children with diabetes using insulin, and AID systems are recommended for children with type 1 diabetes. For this reason, the importance of diabetes 
management in schools is mentioned in the guideline [45]. Because of the coronavirus disease 2019 pandemic, CGM devices have been widely used to minimize contact between health care providers and patients [46-52]. This situation is expected to advance the management of diabetes using technology.

\section{THE MANAGEMENT OF TYPE 1 DIABETES IN ADULTS: A CONSENSUS REPORT BY THE AMERICAN DIABETES ASSOCIATION AND THE EUROPEAN ASSOCIATION FOR THE STUDY OF DIABETES}

Due to the challenges of managing type 1 diabetes and advances in new treatments and technologies, the ADA and European Association for the Study of Diabetes published a consensus report on type 1 diabetes management in October 2021 [53]. An important point in diagnosing type 1 diabetes is to distinguish it from type 2 diabetes and monogenic diabetes. Distinguishing features include younger age ( $<35$ years), lower BMI $\left(<25 \mathrm{~kg} / \mathrm{m}^{2}\right)$, weight loss, ketoacidosis, and glucose $>360 \mathrm{mg} / \mathrm{dL}$ at diagnosis [54]. Rapid progression to insulin treatment ( $<3$ years) is strongly suggestive of type 1 diabetes at any age [55-57]. Beyond 3 years after diagnosis, if there is uncertainty about diabetes type, a random C-peptide measurement with concurrent glucose within 5 hours of eating is recommended [53].

To prevent the development and progression of diabetes complications, it is necessary to maintain glucose levels within an individual's target range. To maintain glucose levels, the effective delivery of exogenous insulin and appropriate indications of glucose levels are important [53]. A1C is an indicator of mean glucose levels, but it does not reflect glycemic variability and hypoglycemia [58,59]. Therefore, capillary blood glucose monitoring plays an important role. According to this report, CGM is the standard method for glucose monitoring (Fig. 2). However, frequent blood glucose monitoring measurements are emphasized in the integrative management of diabetes, regardless of CGM use, because there are concerns that CGM readings do not reflect plasma glucose levels [53].

The treatment of type 1 diabetes involves insulin injections using multiple daily injections or a pump. Insulin therapy with CGM usage leads to improvements in A1C, TIR, and TBR [60]. Currently, an algorithm-driven automated insulin delivery called hybrid closed-loop therapy is used and has shown many improvements $[61,62]$. Fully closed-loop automated insulin delivery systems are under development in both North America and Europe [63]. Type 1 diabetes is a disease with a large burden, so behavior modification is also important in addition to drug therapy. In this report, the importance of diabetes self-management education and support (DSMES) and psychological care are emphasized [64]. Through DSMES, psychological well-being is promoted by providing approaches, treatments, and devices that minimize the psychosocial burden of life. The overall approaches for patients with type 1 diabetes are shown in Fig. 2.

\section{JAPANESE CLINICAL PRACTICE GUIDELINE FOR DIABETES 2019}

Both the 2016 and 2019 Japan Diabetes Society (JDS) clinical practice guidelines include diagnostic criteria for fulminant type $1 \mathrm{DM}$, unlike other guidelines [65]. Patients with fulminant type 1 diabetes frequently develop ketosis or ketoacidosis within 1 week of the onset of hyperglycemia, require insulin therapy immediately, and are characterized as having lower A1C values relative to their glucose values. Patients with fulminant type 1 diabetes are expected to have casual blood glucose values 288 $\mathrm{mg} / \mathrm{dL}$ or higher and A1C values $<8.7 \%$, fasting C-peptide values $<0.3 \mathrm{ng} / \mathrm{mL}$, and post-glucagon load or 2-hour postprandial C-peptide values $<0.5 \mathrm{ng} / \mathrm{mL}$. Affected individuals are expected to test negative for islet autoantibodies [66].

The JDS guideline recommends that glucose-lowering agents are to be chosen in light of their pharmacological and side effect profiles to address each patient's disease condition. There is no priority recommendation for any class of glucose-lowering agents [24]. The JDS guideline emphasizes that the pathophysiology of DM and metformin doses differ in Japanese people, whereas the results for metformin are primarily from trials in Europe and the USA [67]. They conclude that there is insufficient evidence on the effects of GLP-1 RAs and SGLT2 inhibitors on $\mathrm{CV}$ events in Japanese patients since there are racial and pathophysiological differences between Japanese patients and European or American patients [67]. Insulin therapy is implemented in patients with type $2 \mathrm{DM}$ who have inadequate glycemic control despite medical nutrition therapy and therapy with non-insulin glucose-lowering agents, or if hyperglycemia associated glucose toxicity must be eliminated [68]. The guideline gives no cutoff value for $\mathrm{A} 1 \mathrm{C}$ requiring insulin therapy.

Relatively detailed clinical practice guidelines for the treatment of diabetes in the elderly are presented. Elderly patients with DM are mainly characterized as (1) being susceptible to postprandial hyperglycemia and being vulnerable to hypoglycemia; (2) being susceptible to drug-related adverse effects due to factors as such impaired renal function; (3) being likely to have 


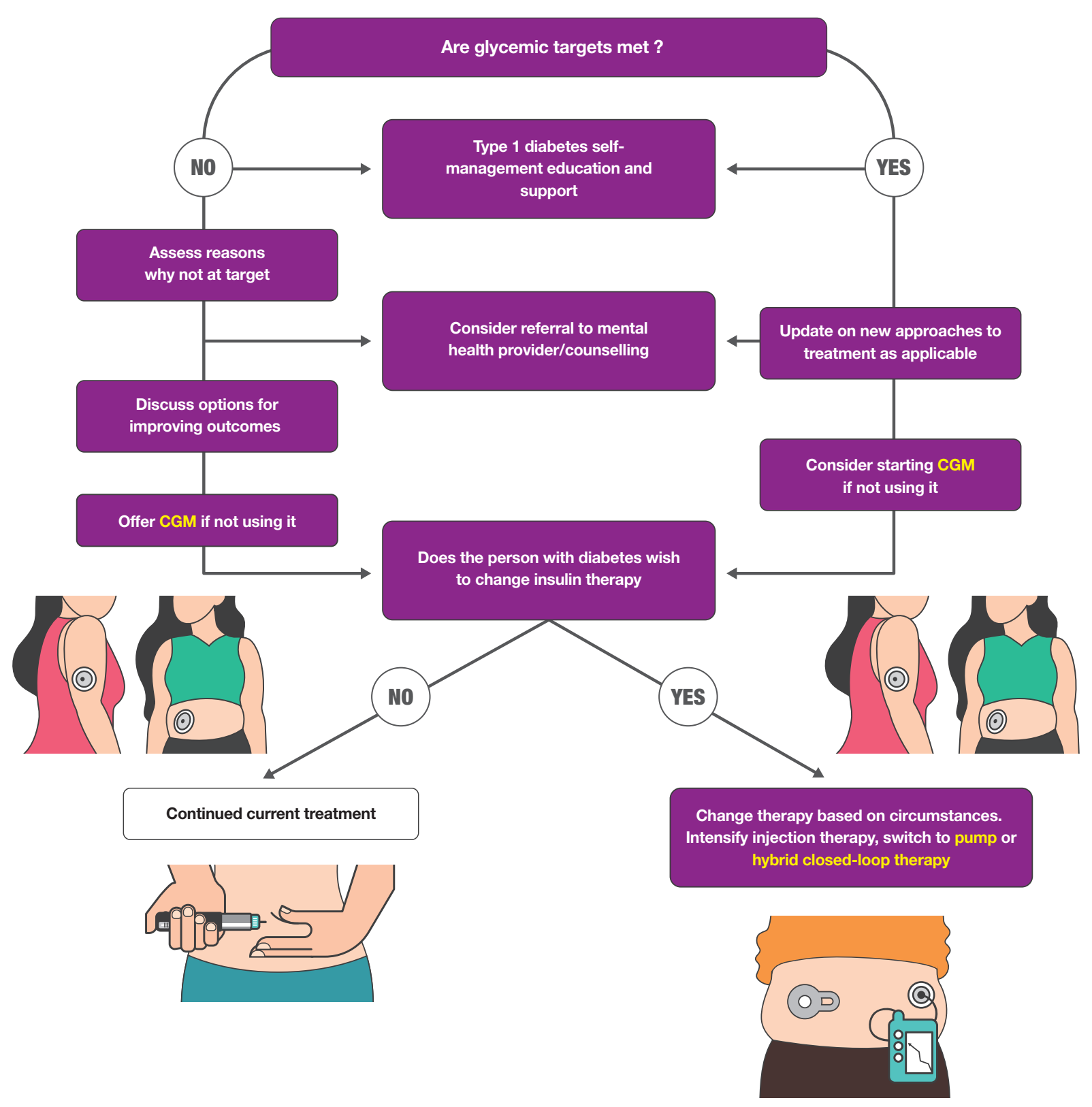

Fig. 2. A framework for the follow-up treatment of an individual with type 1 diabetes. Modified from Holt et al. [53]. CGM, continuous glucose monitoring.

atherosclerotic complications; and (4) being likely to have geriatric syndromes, such as dementia, cognitive impairment, depression, decreased activities of daily living (ADL), and sarcopenia. Appropriate glycemic control focused on ensuring safety, rather than tight glycemic control, should be implemented in elderly patients with diabetes. A glycemic target of $<8.5 \%$ may be allowed in patients thought to have moderate or severe dementia, impairments of ADL, or the presence of multiple comorbidities who are therefore at risk of developing adverse re- actions to multi-drug combination therapy, or in those with serious comorbidities [69].

\section{COMPARISON OF UPDATED GUIDELINES FOR DIABETES MELLITUS}

Although various guidelines present somewhat different glycemic control targets, most guidelines recommend that the glycemic control target should be individualized on the basis of pa- 
tients' clinical characteristics $[1,17,65]$. The threshold for initiating treatment of abnormal lipid levels and the optimal goals of low-density lipoprotein cholesterol (LDL-C) may differ according to ethnicity or population. The KDA [1] and JDS [65] guidelines recommend a somewhat less stringent LDL-C target goal in patients with type 2 DM (Table 1). The JDS guidelines recommend that the primary goal of anti-lipidemic therapy is to control the LDL-C level to $<120 \mathrm{mg} / \mathrm{dL}$ in patients without a history of coronary artery disease [65]. There is no target value of LDL-C in the ADA guidelines. However, there are recommendations on the intensity of statin therapy according to the CV risk; for patients with diabetes aged 40 to 75 years without ASCVD, moderate-intensity statin therapy should be used. High-intensity statin therapy will achieve approximately a $50 \%$ reduction in LDL-C, and moderate-intensity statin regimens achieve $30 \%$ to $49 \%$ reductions in LDL-C.

Metformin remains the mainstay of the initial treatment for type $2 \mathrm{DM}$ for all widely accepted recommendations and is a safe and well-tolerated treatment. The Japanese guideline does not recommend metformin as a first-line agent; instead, it recommends choosing glucose-lowering agents in light of their pharmacological and side effect profiles to address each patient's disease condition [65]. The KDA, ADA, and AACE [17] recommend GLP-1 RAs or SGLT2 inhibitors as an appropriate initial therapy for individuals with type $2 \mathrm{DM}$ with or at highrisk for ASCVD, heart failure, and/or CKD.

The KDA and AACE recommend initiating insulin in symptomatic patients with an $\mathrm{A} 1 \mathrm{C}$ greater than $9 \%$. The ADA recommends that the early introduction of insulin should be considered if there is evidence of ongoing catabolism (weight loss), if symptoms of hyperglycemia are present, or when A1C levels $(>10 \%)$ or blood glucose levels $(\geq 300 \mathrm{mg} / \mathrm{dL})$ are very high. The ADA guideline adds and highlights a new recommendation for the use of combination therapy with insulin and a GLP-1 RA for greater efficacy and durability.

\section{CONCLUSIONS}

Despite the tremendous amount of knowledge and advances in management tools, the quality of diabetes care still falls short of our expectations. Both standardization and individualization based on scientifically sound evidence play a key role in improving care for patients with diabetes, and practice guidelines play a critical role in guiding clinical practitioners. In this review, we summarize the most recent updates, which are also likely to be further adjusted in this rapidly changing era. It is of undoubted importance for clinicians to understand and utilize authorized guidelines as part of diabetes care, and these updates therefore need more attention.

\section{CONFLICTS OF INTEREST}

No potential conflict of interest relevant to this article was reported.

\section{ORCID}

Jin Yu https://orcid.org/0000-0003-4967-9862

Seung-Hwan Lee https://orcid.org/0000-0002-3964-3877

Mee Kyoung Kim https://orcid.org/0000-0003-3205-9114

\section{REFERENCES}

1. Hur KY, Moon MK, Park JS, Kim SK, Lee SH, Yun JS, et al. 2021 Clinical practice guidelines for diabetes mellitus of the Korean Diabetes Association. Diabetes Metab J 2021;45: 461-81.

2. Zinman B, Wanner C, Lachin JM, Fitchett D, Bluhmki E, Hantel S, et al. Empagliflozin, cardiovascular outcomes, and mortality in type 2 diabetes. N Engl J Med 2015;373:211728.

3. Kaku K, Lee J, Mattheus M, Kaspers S, George J, Woerle $\mathrm{HJ}$, et al. Empagliflozin and cardiovascular outcomes in Asian patients with type 2 diabetes and established cardiovascular disease: results from EMPA-REG OUTCOME(R). Circ J 2017;81:227-34.

4. Gerstein HC, Colhoun HM, Dagenais GR, Diaz R, Lakshmanan M, Pais P, et al. Dulaglutide and cardiovascular outcomes in type 2 diabetes (REWIND): a double-blind, randomized placebo-controlled trial. Lancet 2019;394:121-30.

5. Marso SP, Daniels GH, Brown-Frandsen K, Kristensen P, Mann JF, Nauck MA, et al. Liraglutide and cardiovascular outcomes in type 2 diabetes. N Engl J Med 2016;375:31122.

6. Marso SP, Bain SC, Consoli A, Eliaschewitz FG, Jodar E, Leiter LA, et al. Semaglutide and cardiovascular outcomes in patients with type 2 diabetes. N Engl J Med 2016;375: 1834-44.

7. Wiviott SD, Raz I, Bonaca MP, Mosenzon O, Kato ET, Cahn A, et al. Dapagliflozin and cardiovascular outcomes in type 2 diabetes. N Engl J Med 2019;380:347-57.

8. Packer M, Anker SD, Butler J, Filippatos G, Pocock SJ, 
Carson P, et al. Cardiovascular and renal outcomes with empagliflozin in heart failure. N Engl J Med 2020;383:141324.

9. Wanner C, Inzucchi SE, Lachin JM, Fitchett D, von Eynatten M, Mattheus M, et al. Empagliflozin and progression of kidney disease in type 2 diabetes. N Engl J Med 2016;375: 323-34.

10. Heerspink HJ, Stefansson BV, Correa-Rotter R, Chertow GM, Greene T, Hou FF, et al. Dapagliflozin in patients with chronic kidney disease. N Engl J Med 2020;383:1436-46.

11. Musso G, Cassader M, Paschetta E, Gambino R. Thiazolidinediones and advanced liver fibrosis in nonalcoholic steatohepatitis: a meta-analysis. JAMA Intern Med 2017;177: 633-40.

12. Armstrong MJ, Gaunt P, Aithal GP, Barton D, Hull D, Parker R, et al. Liraglutide safety and efficacy in patients with non-alcoholic steatohepatitis (LEAN): a multicentre, double-blind, randomised, placebo-controlled phase 2 study. Lancet 2016;387:679-90.

13. Tang W, Xu Q, Hong T, Tong G, Feng W, Shen S, et al. Comparative efficacy of anti-diabetic agents on nonalcoholic fatty liver disease in patients with type 2 diabetes mellitus: a systematic review and meta-analysis of randomized and non-randomized studies. Diabetes Metab Res Rev 2016; 32:200-16.

14. Heinemann L, Freckmann G, Ehrmann D, Faber-Heinemann G, Guerra S, Waldenmaier D, et al. Real-time continuous glucose monitoring in adults with type 1 diabetes and impaired hypoglycaemia awareness or severe hypoglycaemia treated with multiple daily insulin injections (HypoDE): a multicentre, randomised controlled trial. Lancet 2018;391: 1367-77.

15. Beck RW, Riddlesworth TD, Ruedy K, Ahmann A, Haller S, Kruger D, et al. Continuous glucose monitoring versus usual care in patients with type 2 diabetes receiving multiple daily insulin injections: a randomized trial. Ann Intern Med 2017; 167:365-74.

16. Grunberger G, Sherr J, Allende M, Blevins T, Bode B, Handelsman Y, et al. American Association of Clinical Endocrinology Clinical Practice Guideline: the use of advanced technology in the management of persons with diabetes mellitus. Endocr Pract 2021;27:505-37.

17. Garber AJ, Handelsman Y, Grunberger G, Einhorn D, Abrahamson MJ, Barzilay JI, et al. Consensus statement by the American Association of Clinical Endocrinologists and American College of Endocrinology on the comprehensive type 2 diabetes management algorithm: 2020 executive summary. Endocr Pract 2020;26:107-39.

18. Beck RW, Riddlesworth T, Ruedy K, Ahmann A, Bergenstal $\mathrm{R}$, Haller $\mathrm{S}$, et al. Effect of continuous glucose monitoring on glycemic control in adults with type 1 diabetes using insulin injections: the DIAMOND randomized clinical trial. JAMA 2017;317:371-8.

19. Reddy M, Jugnee N, Anantharaja S, Oliver N. Switching from flash glucose monitoring to continuous glucose monitoring on hypoglycemia in adults with type 1 diabetes at high hypoglycemia risk: the extension phase of the I HART CGM Study. Diabetes Technol Ther 2018;20:751-7.

20. Adolfsson P, Parkin CG, Thomas A, Krinelke LG. Selecting the appropriate continuous glucose monitoring system: a practical approach. Eur Endocrinol 2018;14:24-9.

21. Battelino T, Danne T, Bergenstal RM, Amiel SA, Beck R, Biester T, et al. Clinical targets for continuous glucose monitoring data interpretation: recommendations from the international consensus on time in range. Diabetes Care 2019;42: 1593-603.

22. Ly TT, Nicholas JA, Retterath A, Lim EM, Davis EA, Jones TW. Effect of sensor-augmented insulin pump therapy and automated insulin suspension vs standard insulin pump therapy on hypoglycemia in patients with type 1 diabetes: a randomized clinical trial. JAMA 2013;310:1240-7.

23. Collyns OJ, Meier RA, Betts ZL, Chan DSH, Frampton C, Frewen CM, et al. Improved glycemic outcomes with Medtronic MiniMed Advanced Hybrid Closed-Loop Delivery: results from a randomized crossover trial comparing automated insulin delivery with predictive low glucose suspend in people with type 1 diabetes. Diabetes Care 2021;44: 969-75.

24. American Diabetes Association. Introduction: standards of medical care in diabetes-2022. Diabetes Care 2022;45(Supplement 1):S1-2.

25. American Diabetes Association Professional Practice Committee, Draznin B, Aroda VR, Bakris G, Benson G, Brown FM, et al. Summary of revisions: standards of medical care in diabetes-2022. Diabetes Care 2022;45(Supplement 1):S47.

26. American Diabetes Association Professional Practice Committee, Draznin B, Aroda VR, Bakris G, Benson G, Brown FM, et al. 3. Prevention or delay of type 2 diabetes and associated comorbidities: standards of medical care in diabetes-2022. Diabetes Care 2022;45(Supplement 1):S39-45.

27. American Diabetes Association Professional Practice Com- 
mittee, Draznin B, Aroda VR, Bakris G, Benson G, Brown FM, et al. 7. Diabetes technology: standards of medical care in diabetes-2022. Diabetes Care 2022;45(Supplement 1): S97-112.

28. American Diabetes Association Professional Practice Committee, Draznin B, Aroda VR, Bakris G, Benson G, Brown FM, et al. 9. Pharmacologic approaches to glycemic treatment: standards of medical care in diabetes-2022. Diabetes Care 2022;45(Supplement 1):S125-43.

29. Matthews DR, Paldanius PM, Proot P, Chiang Y, Stumvoll M, Del Prato S, et al. Glycaemic durability of an early combination therapy with vildagliptin and metformin versus sequential metformin monotherapy in newly diagnosed type 2 diabetes (VERIFY): a 5-year, multicentre, randomised, double-blind trial. Lancet 2019;394:1519-29.

30. Aroda VR, Gonzalez-Galvez G, Gron R, Halladin N, Haluzik M, Jermendy G, et al. Durability of insulin degludec plus liraglutide versus insulin glargine U100 as initial injectable therapy in type 2 diabetes (DUAL VIII): a multicentre, open-label, phase $3 \mathrm{~b}$, randomised controlled trial. Lancet Diabetes Endocrinol 2019;7:596-605.

31. Maiorino MI, Chiodini P, Bellastella G, Capuano A, Esposito K, Giugliano D. Insulin and glucagon-like peptide 1 receptor agonist combination therapy in type 2 diabetes: a systematic review and meta-analysis of randomized controlled trials. Diabetes Care 2017;40:614-24.

32. Aroda VR, Rosenstock J, Wysham C, Unger J, Bellido D, Gonzalez-Galvez G, et al. Efficacy and safety of lixilan, a titratable fixed-ratio combination of insulin glargine plus lixisenatide in type 2 diabetes inadequately controlled on basal insulin and metformin: the LixiLan-L randomized trial. Diabetes Care 2016;39:1972-80.

33. Lingvay I, Perez Manghi F, Garcia-Hernandez P, Norwood P, Lehmann L, Tarp-Johansen MJ, et al. Effect of insulin glargine up-titration vs insulin degludec/liraglutide on glycated hemoglobin levels in patients with uncontrolled type 2 diabetes: the DUAL V randomized clinical trial. JAMA 2016;315:898-907.

34. Gerstein HC, Sattar N, Rosenstock J, Ramasundarahettige C, Pratley R, Lopes RD, et al. Cardiovascular and renal outcomes with efpeglenatide in type 2 diabetes. $\mathrm{N}$ Engl J Med 2021;385:896-907.

35. American Diabetes Association Professional Practice Committee, Draznin B, Aroda VR, Bakris G, Benson G, Brown FM, et al. 10. Cardiovascular disease and risk management: standards of medical care in diabetes-2022. Diabetes Care
2022; 45(Supplement 1):S144-74.

36. McMurray JJ, Solomon SD, Inzucchi SE, Kober L, Kosiborod MN, Martinez FA, et al. Dapagliflozin in patients with heart failure and reduced ejection fraction. N Engl J Med 2019;381:1995-2008.

37. Bhatt DL, Szarek M, Steg PG, Cannon CP, Leiter LA, McGuire DK, et al. Sotagliflozin in patients with diabetes and recent worsening heart failure. N Engl J Med 2021;384:11728.

38. Anker SD, Butler J, Filippatos G, Shahzeb Khan M, Ferreira JP, Bocchi E, et al. Baseline characteristics of patients with heart failure with preserved ejection fraction in the EMPEROR-Preserved trial. Eur J Heart Fail 2020;22:2383-92.

39. American Diabetes Association Professional Practice Committee, Draznin B, Aroda VR, Bakris G, Benson G, Brown FM, et al. 11. Chronic kidney disease and risk management: standards of medical care in diabetes-2022. Diabetes Care 2022; 45(Supplement 1):S175-84.

40. Perkovic V, Jardine MJ, Neal B, Bompoint S, Heerspink HJ, Charytan DM, et al. Canagliflozin and renal outcomes in type 2 diabetes and nephropathy. N Engl J Med 2019;380: 2295-306.

41. Bakris GL, Agarwal R, Anker SD, Pitt B, Ruilope LM, Rossing $\mathrm{P}$, et al. Effect of finerenone on chronic kidney disease outcomes in type 2 diabetes. N Engl J Med 2020;383: 2219-29.

42. Filippatos G, Anker SD, Agarwal R, Pitt B, Ruilope LM, Rossing $\mathrm{P}$, et al. Finerenone and cardiovascular outcomes in patients with chronic kidney disease and type 2 diabetes. Circulation 2021;143:540-52.

43. Martens T, Beck RW, Bailey R, Ruedy KJ, Calhoun P, Peters AL, et al. Effect of continuous glucose monitoring on glycemic control in patients with type 2 diabetes treated with basal insulin: a randomized clinical trial. JAMA 2021; 325:2262-72.

44. Price DA, Deng Q, Kipnes M, Beck SE. Episodic real-time CGM use in adults with type 2 diabetes: results of a pilot randomized controlled trial. Diabetes Ther 2021;12:208999.

45. American Diabetes Association Professional Practice Committee, Draznin B, Aroda VR, Bakris G, Benson G, Brown FM, et al. 14. Children and adolescents: standards of medical care in diabetes-2022. Diabetes Care 2022;45(Supplement 1):S208-31.

46. Wallia A, Prince G, Touma E, El Muayed M, Seley JJ. Caring for hospitalized patients with diabetes mellitus, hyper- 
glycemia, and COVID-19: bridging the remaining knowledge gaps. Curr Diab Rep 2020;20:77.

47. Aljehani FA, Funke K, Hermayer KL. Inpatient diabetes and hyperglycemia management protocol in the COVID-19 era. Am J Med Sci 2020;360:423-6.

48. Pasquel FJ, Umpierrez GE. Individualizing inpatient diabetes management during the coronavirus disease 2019 pandemic. J Diabetes Sci Technol 2020;14:705-7.

49. Ceriello A, Standl E, Catrinoiu D, Itzhak B, Lalic NM, Rahelic $\mathrm{D}$, et al. Issues for the management of people with diabetes and COVID-19 in ICU. Cardiovasc Diabetol 2020;19: 114.

50. Korytkowski M, Antinori-Lent K, Drincic A, Hirsch IB, McDonnell ME, Rushakoff R, et al. A pragmatic approach to inpatient diabetes management during the COVID-19 pandemic. J Clin Endocrinol Metab 2020;105:dgaa342.

51. Sadhu AR, Serrano IA, Xu J, Nisar T, Lucier J, Pandya AR, et al. Continuous glucose monitoring in critically ill patients with COVID-19: results of an emergent pilot study. J Diabetes Sci Technol 2020;14:1065-73.

52. American Diabetes Association Professional Practice Committee, Draznin B, Aroda VR, Bakris G, Benson G, Brown FM, et al. 16. Diabetes care in the hospital: standards of medical care in diabetes-2022. Diabetes Care 2022;45(Supplement 1):S244-53.

53. Holt RI, DeVries JH, Hess-Fischl A, Hirsch IB, Kirkman MS, Klupa T, et al. The management of type 1 diabetes in adults: a consensus report by the American Diabetes Association (ADA) and the European Association for the Study of Diabetes (EASD). Diabetes Care 2021;44:2589-625.

54. Shields BM, Peters JL, Cooper C, Lowe J, Knight BA, Powell RJ, et al. Can clinical features be used to differentiate type 1 from type 2 diabetes?: a systematic review of the literature. BMJ Open 2015;5:e009088.

55. Hope SV, Wienand-Barnett S, Shepherd M, King SM, Fox C, Khunti K, et al. Practical classification guidelines for diabetes in patients treated with insulin: a cross-sectional study of the accuracy of diabetes diagnosis. Br J Gen Pract 2016;66: e315-22.

56. Thomas NJ, Lynam AL, Hill AV, Weedon MN, Shields BM, Oram RA, et al. Type 1 diabetes defined by severe insulin deficiency occurs after 30 years of age and is commonly treated as type 2 diabetes. Diabetologia 2019;62:1167-72.

57. Prior MJ, Prout T, Miller D, Ewart R, Kumar D. C-peptide and the classification of diabetes mellitus patients in the Early Treatment Diabetic Retinopathy Study: report number
6. The ETDRS Research Group. Ann Epidemiol 1993;3:917.

58. Beck RW, Connor CG, Mullen DM, Wesley DM, Bergenstal RM. The fallacy of average: how using HbAlc alone to assess glycemic control can be misleading. Diabetes Care 2017;40:994-9.

59. Beck RW, Bergenstal RM, Cheng P, Kollman C, Carlson $\mathrm{AL}$, Johnson ML, et al. The relationships between time in range, hyperglycemia metrics, and HbA1c. J Diabetes Sci Technol 2019;13:614-26.

60. Soupal J, Parkin CG. Response to Comment on Soupal et al. Glycemic outcomes in adults with T1D are impacted more by continuous glucose monitoring than by insulin delivery method: 3 years of follow-up from the COMISAIR Study. Diabetes Care 2020;43:37-43. Diabetes Care 2020;43:e54-5.

61. Bergenstal RM, Garg S, Weinzimer SA, Buckingham BA, Bode BW, Tamborlane WV, et al. Safety of a hybrid closedloop insulin delivery system in patients with type 1 diabetes. JAMA 2016;316:1407-8.

62. Brown SA, Kovatchev BP, Raghinaru D, Lum JW, Buckingham BA, Kudva YC, et al. Six-month randomized, multicenter trial of closed-loop control in type 1 diabetes. $\mathrm{N}$ Engl J Med 2019;381:1707-17.

63. Boughton CK, Hovorka R. The artificial pancreas. Curr Opin Organ Transplant 2020;25:336-42.

64. Beck J, Greenwood DA, Blanton L, Bollinger ST, Butcher MK, Condon JE, et al. 2017 National standards for diabetes self-management education and support. Sci Diabetes Self Manag Care 2021;47:14-29.

65. Araki E, Goto A, Kondo T, Noda M, Noto H, Origasa H, et al. Japanese clinical practice guideline for diabetes 2019. J Diabetes Investig 2020;11:1020-76.

66. Imagawa A, Hanafusa T, Awata T, Ikegami H, Uchigata Y, Osawa H, et al. Report of the committee of the Japan Diabetes Society on the research of fulminant and acute-onset type 1 diabetes mellitus: new diagnostic criteria of fulminant type 1 diabetes mellitus (2012). J Diabetes Investig 2012;3: 536-9.

67. Araki E, Tanaka A, Inagaki N, Ito H, Ueki K, Murohara T, et al. Diagnosis, prevention, and treatment of cardiovascular diseases in people with type 2 diabetes and prediabetes: a consensus statement jointly from the Japanese Circulation Society and the Japan Diabetes Society. Diabetol Int 2020; 12:1-51.

68. Shichiri M, Kishikawa H, Ohkubo Y, Wake N. Long-term results of the Kumamoto Study on optimal diabetes control 
in type 2 diabetic patients. Diabetes Care 2000;23 Suppl 2: B21-9.

69. Japan Diabetes Society (JDS)/Japan Geriatrics Society (JGS)
Joint Committee on Improving Care for Elderly Patients with Diabetes, Haneda M, Ito H. Glycemic targets for elderly patients with diabetes. Diabetol Int 2016;7:331-3. 